\title{
Definition and application of neuropsychological test battery to evaluate postoperative cognitive dysfunction
}

\author{
Definição e aplicação de bateria de testes neuropsicológicos \\ para avaliação de disfunção cognitiva pós-operatória
}

\author{
Lívia Stocco Sanches Valentin ${ }^{1}$, Ricardo Pietrobon ${ }^{2}$, Wagner de Aguiar Junior ${ }^{1}$, Ruth Pinto Camarão Rios ${ }^{1}$, \\ Mariane Galzerano Stahlberg ${ }^{1}$, Iolanda Valois Galvão de Menezes $^{1}$, Kátia Osternack-Pinto ${ }^{1}$, Maria José Carvalho Carmona ${ }^{1}$
}

\begin{abstract}
Objective: To investigate the adequacy of the neuropsychological test battery proposed by the International Study of Postoperative Cognitive Dysfunction to evaluate this disorder in Brazilian elderly patients undergoing surgery under general anesthesia. Methods: A neuropsychological assessment was made in patients undergoing non-cardiac surgery under general anesthesia, aged over 65 years, literate, with no history of psychiatric or neurological problems and score on the Mini Mental State Examination at or above the cutoff point for the Brazilian population ( $>18$ or $>23$ ) according to the schooling level of the subject. Eighty patients were evaluated by a trained team of neuropsychologists up to 24 hours before elective surgery. Results: Among the patients evaluated, one was excluded due to score below the cutoff point in the Mini Mental State Examination and two did not complete the test battery, thus remaining 77 patients in the study. The mean age was $69 \pm 7.5$ years, and $62.34 \%$ of the subjects had \pm 4 years of study. The subjects had significantly lower averages than expected $(p<0.001)$ for normative tables on neuropsychological tests. Conclusion: The study demonstrated the applicability of the instruments in the Brazilian elderly and low schooling level population, but suggested the need to determine cutoff points appropriate for these individuals, ensuring the correct interpretation of results. This battery is relevant to postoperative follow-up evaluations, favoring the diagnosis of postoperative cognitive dysfunction in patients undergoing different types of surgery and anesthetic techniques.
\end{abstract}

Keywords: Cognition disorders; Postoperative period; Anesthesia, general; Neuropsychological tests; Aged

\section{RESUMO}

Objetivo: Investigar a adequação da bateria neuropsicológica proposta pelo International Study of Postoperative Cognitive Dysfunction para a avaliação de disfunção cognitiva pós-operatória em pacientes idosos brasileiros submetidos à cirurgia sob anestesia geral. Métodos: Foi realizada uma avaliação neuropsicológica em pacientes submetidos a cirurgias não cardíacas sob anestesia geral, com idade $>65$ anos, alfabetizados, sem histórico de problemas psiquiátricos ou neurológicos e com pontuação no Miniexame do Estado Mental igual ou superior ao ponto de corte para a população brasileira ( $>18$ ou $>23$ ) de acordo com a escolaridade do sujeito. Oitenta pacientes foram avaliados por equipe treinada de neuropsicólogos até 24 horas antes da cirurgia de caráter eletivo. Resultados: Dentre os pacientes avaliados, um foi excluído por apresentar pontuação abaixo do ponto de corte no Miniexame do Estado Mental e dois não completaram a bateria de testes, permanecendo 77 pacientes no estudo. A média de idade foi de $69 \pm 7,5$ anos, com $62,34 \%$ dos sujeitos, com \pm 4 anos de estudo. Os sujeitos apresentaram médias significativamente inferiores ao esperado $(p<0,001)$ para tabelas normativas nos testes neuropsicológicos. Conclusão: 0 estudo demonstrou a aplicabilidade dos instrumentos na população brasileira idosa e de baixa escolaridade, mas sugeriu a necessidade de determinação de pontos de corte adequados a essa população, garantindo a correta interpretação de resultados. Tal bateria é relevante para avaliações de seguimento pós-cirúrgico, favorecendo o diagnóstico de disfunção cognitiva pós-operatória em pacientes submetidos a diferentes tipos de cirurgia e técnicas anestésicas.

Descritores: Transtornos cognitivos; Período pós-operatório; Anestesia geral; Testes neuropsicológicos; Idoso

\footnotetext{
' Faculdade de Medicina, Universidade de São Paulo, São Paulo, SP, Brazil.

2 Duke University Medical Center, Durham, Carolina do Norte, USA.

Corresponding author: Lívia Stocco Sanches Valentin - Avenida Dr. Enéas de Carvalho Aguiar, 44 - Cerqueira Cesar - Zip code: $05403-001$ - São Paulo, SP, Brazil - Phone: (55 11) 2661-7947 - E-mail: Issv@usp.br Received on: Apr 22, 2014 - Accepted on: Jan 7, 2015
}

Conflict of interest: none.

DOI: 10.1590/\$1679-45082015A03152 


\section{INTRODUCTION}

Postoperative cognitive dysfunction (POCD) following surgery under general anesthesia is a relatively common event, especially in geriatric patients. Although most cases are reversible, in some patients this adverse event may be permanent. Less frequently, some procedures conducted under regional anesthesia may also cause transient cognitive dysfunction in the immediate postoperative period..$^{(1)}$

POCD is defined as a deterioration of the intellectual function with impairment in memory, concentration and daily activities. ${ }^{(2)}$ Most cases of POCD are reported by patients or their families and refer to mnemonic, attentional and behavioral changes, which render uncertain the diagnosis of cognitive dysfunction. ${ }^{(3)}$ The diagnosis of POCD requires pre- and postoperative neuropsychological assessment, which is why we stress the need to assess the patient before surgery. ${ }^{(4,5)}$ This evaluation should include notes on the medication used before surgery and the application of a battery of specific neuropsychological tests that measure cognitive and emotional function.

POCD-related factors are the use of opioids after surgery, lack of physical activity, postoperative fatigue, postoperative pain, depression and quality of life. ${ }^{(6,7)}$ Some medications can aggravate POCD, such as the continuous use of benzodiazepines, sedatives, antidepressants and anti-Parkinson drugs before surgery. ${ }^{(8,9)}$

The incidence of POCD is high $(40 \%)$ in patients over 65 years undergoing medium and large surgeries; in cardiac surgery, this percentage may be higher than $60 \%{ }^{(10-12)}$ The risk factors are not yet fully defined, neither the importance of each of these factors in the development and evolution of this neuropsychological complication, which often predisposes to comorbidities, increasing the possibility of mortality of surgical patients. ${ }^{(13,14)}$

In Brazil, in recent decades, there was a rapid growth of the elderly population. In 1970, this population represented approximately $3.7 \%$ of the total population of the country, and in 2000, this percentage increased to $5.2 \%$. It is estimated that by 2025 the elderly will comprise $10.4 \%$ of the total population, and by 2050 , this rate will reach $18.3 \% .^{(15)}$ The growth of the elderly population accounts for $42 \%$ of medical consultations and $50 \%$ of hospitalizations. The elderly suffer from most diseases that require special attention and often surgery. ${ }^{(16)}$

It is necessary to adjust the neuropsychological tools capable of detecting POCD in the elderly population is, providing data for the development of new studies aiming to offer the elderly a better and faster recovery in the postoperative period.

\section{OBJECTIVE}

To investigate the adequacy of a battery of neuropsychological tests to detect cognitive dysfunction in the postoperative period in Brazilian elderly patients candidates for surgery under general anesthesia, using the protocol proposed by the International Study of Postoperative Cognitive Dysfunction.

\section{METHODS}

On August 1st, 2007, the study was approved by the Ethics Committee for Research Project Analysis (CAPPesq) of the Clinical Board, Hospital das Clínicas da Faculdade de Medicina da Universidade de São Paulo (HC-FMUSP). The study registered under the number 998/06 was conducted at the Instituto Central do HC-FMUSP. The statistical analysis for the results of the neuropsychological tests had the collaboration of Duke University, North Carolina, United States. After reading and signing the Informed Consent Form patients candidate to surgery under general anesthesia were evaluated by neuropsychologists. Patient recruitment was carried out by non-probability sampling technique for convenience, and 80 elderly were selected by the head of the unit, who was in charge of the surgical program, through daily screening of patients eligible for surgery. These subjects were selected by the inclusion criteria, considering demographic data (age, schooling level, type of surgery, type of anesthesia and clinical conditions), according to the surgical scheduling system of the HC-FMUSP, to comprise a sufficient sample to show the efficacy of the neuropsychological test battery of the International Study of Postoperative Cognitive Dysfunction (ISPOCD1) for the Brazilian elderly population undergoing surgery under general anesthesia (Figure 1).

A total of 77 patients, aged 65 years, who underwent medium-sized surgeries under general anesthesia were included; two patients who did not achieve the minimum score $(>18)$ on the Mini Mental State Examination (MMSE), and one that declined participation in the study after the invitation and signing the informed consent form were excluded. Other exclusion criteria were a history of brain disease or dementia, among other psychiatric disorders that affect cognition, lack of knowledge of Portuguese, and use of corticosteroids or opioid drugs in the preoperative period. The first interview, the application of a socio-demographic questionnaire, the MMSE test and the invitation to participate in the study were conducted by volunteer 


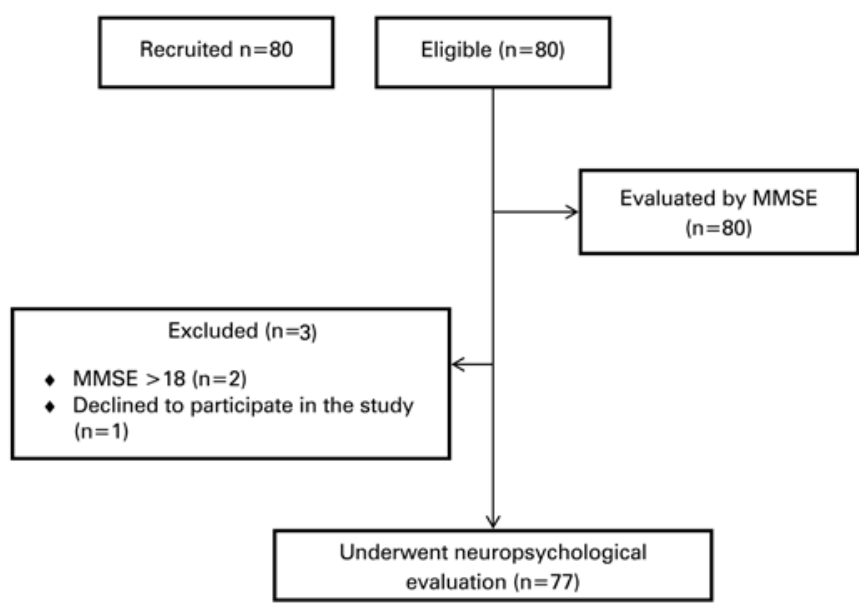

MMSE: Mini Mental State Examination.

Figure 1. Composition of the sample according to inclusion criteria

neuropsychologists who were experienced in medical research before administering neuropsychological tests. All elderly people signed the informed consent form and underwent a preoperative evaluation the day before surgery. All tests and questionnaires were directed by an experienced examiner.

The preoperative evaluation included a sociodemographic questionnaire to collect information on age, sex, education, marital status, occupation and other relevant information to compose the sample profile, created for the research project after this preliminary study, the MMSE test and other neuropsychological tests described below. The socio-demographic questionnaire was completed by the examiner, a neuropsychologist engaged in the research, with answers provided by the patient. Neuropsychological tests and the MMSE were completed by the patient through oral answers on request recorded by the researcher in the test answer sheet, or the graphic or written production, depending on the construct, by the patient in the answer sheet test.

The MMSE test, which assesses reasoning, spatialtemporal orientation, memory and education was used to screen patients for enrollment in the study. The cutoff point of this instrument, for the Brazilian population, is considered for two types of schooling: up to 4 years of formal academic study and more than 4 years of schooling, with a cutoff point of 18 for the less educated and over 23 points for individuals with higher levels of education. ${ }^{(17-19)}$

The Telephone Interview for Cognitive Status (TICS) is a standardized test to evaluate neuropsychological functioning and used when a personal evaluation of global cognitive function is impractical or inefficient, for example, in epidemiological studies of large populations or in patients who are unable to attend the clinical follow- up visits. It may also be applicable in patients unable to read or write, only requiring verbal comprehension. The test consists of an interview script with 11 items that assess spatial and temporal orientation skills, mind control, memory, general information, language and calculations. ${ }^{(20-22)}$

The Verbal Learning Test (VLT) consists of a list of 15 words to be memorized and recalled in three successive attempts (VLT/A-B-C), with delayed recall after 15 to 25 minutes (VLT-D). The number of recalled words and the number of errors for each presentation are evaluated. The VLT assesses the modalities of memory: immediate, consolidated and long-term. ${ }^{(23,24)}$

The Symbol Digit Modalities Test (SDMT) assesses short-term memory, visual-spatial ability and attention. It also assesses the individual's ability to organize, plan and seek strategies to carry out the task in less time and with greater amount of symbols in 180 seconds, i.e., the executive function skills. The individual has to reproduce the symbols exemplified in a card in the spaces below the corresponding numbers. ${ }^{(25,26)}$

The Trail Making Test (TMT) consists of parts A and B. The subject must draw lines connecting consecutively numbered circles in part A. In part B, the subject must draw lines alternately connecting circles with letters and numbers in an increasing sequence. Besides alternate and selective attention, the test involves complex visual screening and manual dexterity (Part A), and executive processes (Part B). Among the executive processes, inhibitory ability and cognitive alternation seem to be those most required in performing the task. Time and number of errors are evaluated in each part. ${ }^{(27,28)}$

The Stroop Card Word and Color Test (SCWCT) is conducted presenting three cards to the subject being evaluated. In the first card, the subject must say the names of the colors printed in black ink. In the second, the subject must say the names of the colors filling a series of rectangles, arranged the same as the words in the former card. In the third card, the subject must say the names of the colors printed independently of the written word. The purpose of the test is to assess selective attention, inhibitory ability and mental flexibility. The time taken to complete the test and the number of errors on each card are evaluated. ${ }^{26,29-31)}$

The variables analyzed were schooling, wage rate, occupation, sex, marital status and the cognitive functions of memory and attention.

The statistical analysis was performed using the Shapiro-Wilk tests to ensure the normality of the sample, and the Spearman correlation coefficient was used to verify the possible correlation between the results of neuropsychological tests and the schooling 
level of the study subjects. The data were presented as mean and standard deviation, or median and maximum and minimum in simple descriptive analysis. $\mathrm{P}$ values $<0.05$ were considered significant.

\section{RESULTS}

According to figure 1 , we recruited 80 patients with a fitting profile to participate in the study, according to the inclusion criteria. The remaining 77 patients were evaluated by a professional with experience in the application of neuropsychological tests and in clinical research using a neuropsychological test battery (TICS, VLT, SDMT, TMT, SCWCT).

Since the objective of this study was to define a battery of neuropsychological tests applicable to the Brazilian elderly population requiring surgery under general anesthesia, we correlated schooling level, wage rate, employment situation, sex and marital status at the time of assessment to POCD.

The predominant family income was in the range of two to five minimum wages corresponding to $70.1 \%$ of the sample; the marital status of $59.7 \%$ of patients was married, and females comprised $66.2 \%$ of the sample (Table 1).

The main neuropsychological functions assessed were global cognitive function, MMSE and TICS tests. The averages presented by subjects were consistent with normative data for world population $(25 \pm 3.3$; $27.7 \pm 3.3)$.

Sustained attention was evaluated by TMT-A and SCWT-A tests, and quantitative interpretation of the results of these tests were the time taken to complete the test in seconds and the SDMT, rated according to the amount of correct digits written by the subjects during the standard task time $(115.3 \pm 47.6 ; 83.3 \pm 42.6$ and $33.8 \pm 18.9$, respectively). For alternating attention, the TMT-B and SCWT-C test were used, and the evaluation of the results was done according to the time taken to perform the task $(259.6 \pm 160.3 ; 99 \pm 35)$.

Memory and the ability to learn new content, as well as the executive function for inhibitory control and the strategy for solving problems, were evaluated by the VLT and SCWT-B tests. The appraisal of results was done according to the time taken in seconds, and the amount of mistakes made by the individual during the execution of the task.

Most of the elderly in this study, when compared to elderly of the same age on validated tables, had lower scores. However, when compared with each other, the values were similar ( $p>0.001$ ), allowing us to infer that the tests could be adjusted to the Brazilian population, provided normative guidelines were used
Table 1. Socio demographic data on schooling

\begin{tabular}{|c|c|c|c|c|c|c|c|c|}
\hline $\begin{array}{l}\text { Schooling } \\
\text { (years) }\end{array}$ & $\leq 2$ & $\leq 5$ & $\leq 7$ & $\leq 9$ & $\geq 11$ & $\geq 15$ & n (77) & $\begin{array}{c}p \\
\text { value }\end{array}$ \\
\hline Wage ${ }^{*}$ & & & & & & & & 0.9 \\
\hline 1 & 6 & 1 & - & - & - & - & 7 & \\
\hline $2-5$ & 37 & 6 & 2 & 6 & 3 & - & 54 & \\
\hline $6-10$ & 3 & 3 & - & 2 & 1 & 2 & 11 & \\
\hline $11-15$ & 2 & - & - & 2 & - & - & 4 & \\
\hline $16-20$ & - & - & - & - & - & 1 & 1 & \\
\hline Employment & & & & & & & & 0.8 \\
\hline Retired & 30 & 9 & 2 & 6 & 3 & 3 & 53 & \\
\hline Unemployed & 11 & - & - & 3 & - & - & 14 & \\
\hline Employed & 2 & - & - & 1 & 1 & - & 4 & \\
\hline Eventual & 5 & 1 & - & - & - & - & 6 & \\
\hline Marital status & & & & & & & & 0.8 \\
\hline Single & 4 & - & - & 2 & - & - & 6 & \\
\hline Married & 28 & 5 & 2 & 7 & 1 & 3 & 46 & \\
\hline Divorced & 5 & 2 & - & - & 1 & - & 8 & \\
\hline Widowed & 10 & 2 & - & 1 & 1 & - & 14 & \\
\hline Cohabiting & 1 & 1 & - & 0 & 1 & - & 3 & \\
\hline Sex & & & & & & & & 0.7 \\
\hline Male & 15 & 4 & - & 3 & 4 & - & 26 & \\
\hline Female & 33 & 6 & 2 & 7 & - & 3 & 51 & \\
\hline
\end{tabular}

for the assessment and diagnosis of cognitive functions (Table 2).

The test results showed a significant correlation with education and with the age of the subjects. There was a positive correlation between schooling level and mnemonic function, showing that the higher the education level, the greater the memory storage capacity (VLT-1; $\mathrm{r}=0.8 ; \mathrm{p}<0.0001$ ). However, a negative correlation between attention and executive function and schooling was observed (TMT-A; $\mathrm{r}-0.7 ; \mathrm{p}=0.03 \mathrm{e}$ SCWT-A; $r=-0.7 ; p=0.05$ ) (Table 3).

Although largely used in the international population, many tests have the consent of their authors to be adapted for the study populations, because the results vary from population to population. The patients in this study had MMSE test scores compatible with the normative points expected by schooling and age. For 60-64-year-old individuals, with up to 4 years of schooling, the cutoff point is 22 (1.9); for the age group 65-69 years, the expected score is 22 (1.7); and for subjects aged 70 to 74 , the expected score is 20 (2). In the same age groups, with 5-8 years of schooling, the cutoff points and respective standard deviations are 26 (1.7), 26 (1.8) and 25 (2.1). For individuals with 9-12 years or more of schooling, the expected scores are 28 (1.4), 27 (1.6), 27 (1.5), respectively. 
Table 2. Main cognitive functions assessed and corresponding tests

\begin{tabular}{lccccc}
\hline Test & Assessed function & M & SD & Minimum & Maximum \\
\hline MMSE & Global cognitive function & 25 & 3.3 & 16 & 30 \\
TICS & Global cognitive function & 27.7 & 3.3 & 16 & 36 \\
SDMT & Selective attention & 33.8 & 18.9 & - & 82 \\
TMT-A & Focused attention & $115.3^{*}$ & 47.6 & 15 & 273 \\
TMT-B & Alternating attention & $259.6^{*}$ & 160.3 & 69 & 869 \\
VLT-1 & Memory and learning & $5.4^{* *}$ & 2.2 & 1 & 12 \\
VLT-2 & Memory and learning & $7^{* *}$ & 1.8 & 3 & 11 \\
VLT-3 & Memory and learning & $8.3^{* *}$ & 1.9 & 4 & 13 \\
VLT-D & Memory and learning & $6.7^{* *}$ & 2.8 & - & 14 \\
SCWT-A & Sustained attention & $83.3^{*}$ & 42.6 & 20 & 164 \\
SCWT-B & Selective attention & $51^{*}$ & 18.2 & 22 & 132 \\
SCWT-C & Alternating attention & $99^{*}$ & 35 & 42 & 231 \\
\hline
\end{tabular}

Data as mean (SD) and minimum and maximum. *Results as time (seconds): ** Results as number of words. M: mean, SD: standard deviation; MMSE: Mini Mental State Examination; TICS: Telephone Interview Cognitive Status; SDMT: Symbol Digit Modified Test; TMT: Trail Making Test; VLT: Verbal Learning Test; SCWT: Stroop Color Word Test.

Table 3. Correlation between neuropsychological tests and schooling level

\begin{tabular}{lcc}
\hline Neuropsychological test & $\mathbf{r}$ & $\mathbf{p}$ value \\
\hline MMSE & $0.2^{* *}$ & 0.02 \\
TICS & $0.7^{*}$ & 0.00 \\
VLT-1 & $0.8^{*}$ & 0.00 \\
VLT-2 & $0.6^{*}$ & 0.00 \\
VLT-3 & $0.6^{*}$ & 0.00 \\
VLT-D & $0.7^{*}$ & 0.04 \\
SCWT-A & $-0.7^{*}$ & 0.05 \\
SCWT-B & $-0.5^{* *}$ & 0.05 \\
SCWT-C & $-0.5^{* *}$ & 0.05 \\
TMT-A & $-0.7^{*}$ & 0.03 \\
TMT-B & $-0.6^{* *}$ & 0.02 \\
SDMT & $0.7^{*}$ & 0.04
\end{tabular}

rand $p$ values by the Spearman correlation test; ${ }^{*} r=0.7$ for more or less indicated a strong correlation, ${ }^{*}{ }^{*}=0.3$ to 0.7 positive or negative indicated a moderate correlation. $p>0.005$ was considered significant. MMSE: Mini Mental State Examination; TICS: Telephone Interview Cognitive Status; VLT: Verbal Learning Test; SCWT: Stroop Color Word Test; TMT: Trail Making Test; SDMT: Symbol Digit Modified Test.

For executive functioning, the SDMT test has a cutoff point of 46.79 (8.08) for subjects aged over 50 and up to 12 years of formal education. For focused attention, the Trail Making Test part A renders a score of 24 to 60 , for 64-69- year-old subjects, with percentiles in descending order; and for part B, 56-137 points, also with percentile 10 for longer completion times in seconds. For 70-74-year-old subjects, the completion times expected for part A are 25-57 seconds, and for part $\mathrm{B}, 70-172$ seconds.

A total of 77 patients remained, with mean age of $67.0 \pm 6.35$ years and $7.1 \pm 4.42$ years of study.

The statistical analysis was based on data obtained from those 77 patients. The mean values and standard deviations of the scores of the instruments administered in the immediate preoperative period were compared with the values expected from the standard scores. Test results were correlated with schooling to check if elderly Brazilians were able to perform the tests that were adapted from the ISPOCD1 study.

Compared to international standards, the mean values of the tests were similar to those expected for age and education only in VLT test, which evaluates memory. All other results were significantly lower than expected. The time used in the TMT Parts A and B corresponded to a percentile $<10$, and the scores obtained in both SCWT and SDMT tests were over 2 standard deviations below the average.

\section{DISCUSSION}

The battery of neuropsychological tests used in ISPOCD1 adapted for this study was sensitive to detect POCD in the elderly. Most neuropsychological tests were developed in English speaking countries and therefore should be adapted and validated to the culture of the country that will make use of these instruments in order to show, in a reliable manner, possible cognitive dysfunctions and the preservation of these functions.

In a study on cataract surgery, neuropsychological tests were adapted to the patients because some patients had reading problems. In another study with orthopedic patients, most of the tests that measured manual psychomotor speed were replaced by others when the patients had to receive an intravenous infusion in the dominant arm. ${ }^{(5,32)}$ In POCD studies, the cognitive functions are evaluated by various neuropsychological tests. A suitable test is characterized by a high sensitivity, as confirmed from various studies and their applicability, e.g., the test should be able to detect the effects of factors that undoubtedly affect brain functioning, such as medication and age. ${ }^{(33)}$

Neuropsychological tests were not designed to investigate cognitive impairment in surgical patients, and many of them do not detect subtle cognitive impairment. ${ }^{(20,34)}$ The sensitivity of the tests for these cases seems to be very low, therefore POCD studies use several batteries with various neuropsychological tests, but they are not capable of detecting postoperative cognitive decline or any difference between the groups; there is no specific and standardized battery for POCD. ${ }^{(14,35)}$

Elderly individuals show a decrease in the functional reserves of several organs and systems, and consequently have reduced tolerance to the requirements represented by the anesthetic-surgical stress. ${ }^{(36,37)}$ The tests used in this study were suitable to assess previous cognitive 
dysfunctions in elderly patients undergoing elective surgery under general anesthesia.

Throughout this study, we observed some characteristics related to the productivity of the elderly in the batteries of neuropsychological tests, who have reduced ability to tolerate tasks that require reasoning and concentration for a long time, and should have appropriate instruments to minimize the influence of fatigue.

The articles searched demonstrated that there is variability in the tests used and heterogeneity among the selection criteria for them, and further studies and investigations are needed to eliminate methodological limitations to ensure a better use of the results. ${ }^{(38)}$

Aside from the results of the memory test (VLT), all other results of the pilot study were significantly lower than the normative standards. Although the sample is small, the study highlights the importance of establishing national standards, considering the cognitive and cultural characteristics of the population. Edited versions of neuropsychological tests that do not go through a proper validation process may result in assessments with no reliable parameters for the results.

Since this was a pilot study, this research was limited to assessing patients before surgery. Other studies under the same research project were conducted at the Instituto Central do Hospital das Clínicas da Faculdade de Medicina da Universidade de São Paulo, in partnership with Duke University, continuing the study of cognitive dysfunction in the postoperative period in elderly patients undergoing surgery under general anesthesia. The same battery of neuropsychological tests adapted to Brazilian population was used and other aspects were assessed, such as anesthetic depth, type of anesthesia, anesthetic techniques, schooling, age and previous use of corticosteroids as a preventive measure for cognitive dysfunction in the postoperative period. These studies demonstrated the efficiency and practicality of using this neuropsychological test battery for cognitive dysfunction detection postoperatively.

\section{CONCLUSION}

This study demonstrated the applicability of the instruments in the elderly Brazilian population with low schooling level, but suggested the need to determine appropriate cutoff points for this population, ensuring the correct interpretation of the results. This battery is relevant to follow-up evaluations after surgery, favoring the diagnosis of postoperative cognitive dysfunction in patients undergoing different types of surgery and anesthetic techniques.

\section{ACKNOWLEDGEMENTS}

Research support from Fundação de Amparo à Pesquisa do Estado de São Paulo (FAPESP), [The State of São Paulo Research Foundation], no 09/54233-0. We are especially thankful to the collaboration of Dr Terri G. Monk, MD, MS, geriatric anesthesiologist and clinical researcher, who conducted studies on cognitive changes after anesthesia and surgery, and opened space for our research at the Veterans Affairs Hospital - Duke University, in Durham, North Carolina. She was always willing to answer questions about the heterogeneity of the study samples in Brazilian and American populations.

\section{REFERENCES}

1. Canet J, Raeder J, Rasmussen LS, Enlund M, Kuipers HM, Hanning CD, Jolles J, Korttila K, Siersma VD, Dodds C, Abildstrom H, Sneyd JR, Vila P, Johnson T, Muñoz Corsini L, Silverstein JH, Nielsen IK, Moller JT; ISPOCD2 investigators. Cognitive dysfunction after minor surgery in the elderly. Acta Anaesthesiol Scand. 2003;47(10):1204-10.

2. Krenk L, Rasmussen LS. Postoperative delirium and postoperative cognitive dysfunction in the elderly - what are the differences? Minerva Anestesiol. 2011;77(7):742-9. Review.

3. Tsai TL, Sands LP, Leung JM. An Update on Postoperative Cognitive Dysfunction. Adv Anesth. 2010;28(1):269-84.

4. Silverstein JH, SteinmetzJ, Reichenberg A, HarveyPD, Rasmussen LS. Postoperative cognitive dysfunction in patients with preoperative cognitive impairment: which domains are most vulnerable? Anesthesiology. 2007;106(3):431-5.

5. Rasmussen LS. Defining postoperative cognitive dysfunction. Eur J Anaesthesiol. 1998;15(6):761-4.

6. Phillips-Bute B, Mathew JP, Blumenthal JA, Grocott HP, Laskowitz DT, Jones $\mathrm{RH}$, et al. Association of neurocognitive function and quality of life 1 year after coronary artery bypass graft (CABG) surgery. Psychosom Med. 2006;68(3):369-75

7. Bolognini N, Rossetti A, Casati C, Mancini F, Vallar G. Neuromodulation of multisensory perception: a tDCS study of the sound-induced flash illusion. Neuropsychologia. 2011;49(2):231-7.

8. Edwards DJ, Krebs HI, Rykman A, Zipse J, Thickbroom GW, Mastaglia FL, et al. Raised corticomotor excitability of M1 forearm area following anodal tDCS is sustained during robotic wrist therapy in chronic stroke. Restor Neurol Neurosci. 2009;27(3):199-207.

9. Pratico C, Quattrone D, Lucanto T, Amato A, Penna O, Roscitano C, et al. Drugs of anesthesia acting on central cholinergic system may cause post-operative cognitive dysfunction and delirium. Medical hypotheses. 2005;65(5):972-82.

10. Newfield P. Postoperative cognitive dysfunction. F1000 Med Rep. 2009;1. PubMed PMID: 20948768.

11. Martin JF, Melo RO, Sousa LP. Postoperative cognitive dysfunction after cardiac surgery. Rev Bras Cir Cardiovasc. 2008;23(2):245-55. Review. English.

12. Bruggemans EF. Cognitive dysfunction after cardiac surgery: Pathophysiological mechanisms and preventive strategies. Neth Heart J. 2013;21(2):70-3.

13. Benoit AG, Campbell BI, Tanner JR, Staley JD, Wallbridge HR, Biehl DR, et al. Risk factors and prevalence of perioperative cognitive dysfunction in abdominal aneurysm patients. J Vasc Surg. 2005;42(5):884-90.

14. Ramaiah R, Lam AM. Postoperative cognitive dysfunction in the elderly. Anesthesiol Clin. 2009;27(3):485-96, table of contents. Review.

15. Abrantes VL. [The photographic archive of the Instituto Brasileiro de Geografia e Estatistica and Tibor Jablonszky's view of female labor]. Hist Cienc Saude Manguinhos. 2013;20(1):289-306. Portuguese. 
16. Suzman RBJ. Global Health Aging. Geneva: World Health Organization; 2010.

17. Jacinto AF, Brucki SM, Porto CS, Martins Mde A, Citero Vde A, Nitrini R. Suggested instruments for General Practitioners in countries with low schooling to screen for cognitive impairment in the elderly. Int Psychogeriatr. 2014;26(7):1121-5.

18. Brucki SM, Nitrini R, Caramelli P, Bertolucci PH, Okamoto IH. [Suggestions for utilization of the mini-mental state examination in Brazil]. Arq Neuropsiquiatr. 2003;61 (3B):777-81. Portuguese.

19. Bertolucci PH, Brucki SM, Campacci SR, Juliano Y. [The Mini-Mental State Examination in a general population: impact of educational status]. Arq Neuropsiquiatr. 1994;52(1):1-7. Portuguese.

20. Fong TG, Fearing MA, Jones RN, Shi P, Marcantonio ER, Rudolph JL, et al. Telephone interview for cognitive status: Creating a crosswalk with the MiniMental State Examination. Alzheimers Dement. 2009;5(6):492-7.

21. Lopez OL, Kuller LH. Telephone interview for cognitive status. Neuroepidemiology. 2010;34(1):63-4.

22. Ferrucci L, Del Lungo I, Guralnik JM, Bandinelli S, Benvenuti E, Salani B, et al. Is the telephone interview for cognitive status a valid alternative in persons who cannot be evaluated by the Mini Mental State Examination? Aging (Milano). 1998;10(4):332-8.

23. Miotto EC, Campanholo KR, Rodrigues MM, Serrao VT, Lucia MC, Scaff M. Hopkins verbal learning test-revised and brief visuospatial memory test-revised: preliminary normative data for the Brazilian population. Arq Neuropsiquiatr. 2012;70(12):962-5.

24. Greve KW, Curtis KL, Bianchini KJ, Ord JS. Are the original and second edition of the California Verbal Learning Test equally accurate in detecting malingering? Assessment. 2009;16(3):237-48.

25. Lezak MD. Neuropsychological assessment in behavioral toxicology--developing techniques and interpretative issues. Scand J Work Environ Health. 1984;10 Suppl 1:25-9.

26. Van der Elst W, Van Boxtel MP, Van Breukelen GJ, Jolles J. Detecting the significance of changes in performance on the Stroop Color-Word Test, Rey's Verbal Learning Test, and the Letter Digit Substitution Test: the regressionbased change approach. J Int Neuropsychol Soc. 2008;14(1):71-80.
27. Tombaugh TN. Trail Making Test A and B: normative data stratified by age and education. Arch Clin Neuropsychol. 2004;19(2):203-14.

28. Arbuthnott K, Frank J. Trail making test, part B as a measure of executive control: validation using a set-switching paradigm. J Clin Exp Neuropsychol. 2000;22(4):518-28.

29. Bondi MW, Serody AB, Chan AS, Eberson-Shumate SC, Delis DC, Hansen $L A$, et al. Cognitive and neuropathologic correlates of Stroop Color-Word Test performance in Alzheimer's disease. Neuropsychology. 2002;16(3):335-43.

30. Kukull WA, Larson EB, Teri L, Bowen J, McCormick W, Pfanschmidt ML. The mini-mental state examination score and the clinical diagnosis of dementia. J Clin Epidemiol. 1994;47(9):1061-7.

31. Strauss E, Sherman EM, Spreen O. A compendium of neuropsychological tests: administration, norms, and commentary. $3^{\text {rd }}$ ed. Oxford: Oxford University Press; 2006.

32. Moller JT, Cluitmans P, Rasmussen LS, Houx P, Rasmussen H, Canet J, et al. Long-term postoperative cognitive dysfunction in the elderly ISPOCD1 study. ISPOCD investigators. International Study of Post-Operative Cognitive Dysfunction. Lancet. 1998;351(9106):857-61. Erratum in: Lancet 1998;351(9117):1742.

33. Anwer HM, Swelem SE, el-Sheshai A, Moustafa AA. Postoperative cognitive dysfunction in adult and elderly patients--general anesthesia vs subarachnoid or epidural analgesia. Middle East J Anesthesiol. 2006;18(6):1123-38.

34. Knopman DS, Roberts RO, Geda YE, Pankratz VS, Christianson TJ, Petersen $\mathrm{RC}$, et al. Validation of the telephone interview for cognitive status-modified in subjects with normal cognition, mild cognitive impairment, or dementia. Neuroepidemiology. 2010;34(1):34-42.

35. Funder KS, Steinmetz J, Rasmussen LS. Cognitive dysfunction after cardiovascular surgery. Minerva Anestesiol. 2009;75(5):329-32. Review.

36. Linstedt U, Meyer 0, Kropp P, Berkau A, Tapp E, Zenz M. Serum concentration of S-100 protein in assessment of cognitive dysfunction after general anesthesia in different types of surgery. Acta Anaesthesiol Scand. 2002;46(4):384-9.

37. Bekker AY, Weeks EJ. Cognitive function after anaesthesia in the elderly. Best Pract Res Clin Anaesthesiol. 2003;17(2):259-72. Review.

38. Newman S, Stygall J, Hirani S, Shaefi S, Maze M. Postoperative cognitive dysfunction after noncardiac surgery: a systematic review. Anesthesiology. 2007;106(3):572-90. Review. 